\title{
Management of un-ruptured pregnancy in a rudimentary horn of unicornuate uterus at 14 weeks gestation
}

\author{
Costas Panayotidis • Sanjay Prabhu
}

Received: 4 November 2006 / Accepted: 13 February 2007 / Published online: 20 March 2007

(C) Springer-Verlag 2007

\begin{abstract}
We present a case of missed miscarriage in an unsuspected non communicating rudimentary horn on a unicornuate uterus. The difficulties of the diagnosis and management of such congenital malformation are described.
\end{abstract}

Keywords Rudimentary uterine horn · Miscarriage . Laparoscopy

\section{Case study}

A 23-year-old primigravida at 14 weeks pregnant attended the early pregnancy unit with blood spotting per vagina. She had no significant past medical and surgical history. She appeared well and was haemodynamically stable. The ultrasound scan confirmed a missed miscarriage corresponding to 12 weeks pregnancy with no cardiac activity in an apparent bicornuate uterus. There was no adnexal mass or free fluid. The vaginal examination did not reveal any abnormality and her cervix was normal.

She opted for medical method of evacuation of non viable pregnancy. She had 3 cycles of misoprostol but without success with no further per vaginal bleeding. The surgical method of evacuation was considered under ultrasound guidance and on suction evacuation no products of conception obtained. The tip of the suction canula could not reach the fetal pole. The possibility of a rudimentary horn was then considered and on the subsequent day she

C. Panayotidis $(\bowtie) \cdot$ S. Prabhu

Department of Obstetrics \& Gynaecology,

Royal Preston Hospital,

Preston, UK

e-mail: costapan@hotmail.com consented for a diagnostic laparoscopy and query proceeds of laparotomy for excision of rudimentary horn. She continued to be asymptomatic. The laparoscopy revealed a unicornuate uterus with normal right side horn (Fig. 1a,b). To the left side of the uterus a rudimentary horn was present with an intact round ligament and fallopian tube. This left part of the uterus held the pregnancy, was dilated, inflamed and without signs of rupture (Fig. 2). Both the ovaries were normal and diffuse mild pelvic endometriosis was noted. Laparotomy was done through a Pfannenstiel incision and the rudimentary horn excised. It was found to be non-communicating. The cut section of the specimen contained an intact dead foetus of appreciatively 12 weeks (see photo Fig. 3). The patient recovered without complication in 3 days. Further consultation about fertility issues and exclusion of urinary tractus abnormalities was organised.

\section{Discussion}

\section{Background}

Unicornuate uterus with pregnancy in a rudimentary horn is an extremely rare clinical scenario that often surprises the gynaecologist or obstetrician. A rudimentary horn is a rare type of congenital uterine anomaly and occurs due to noncoordinated development of one of the mullerian ducts which arrests and fails to fuse with its equivalent on the other side during embryogenesis. The exact incidence of unicornuate uterus is unknown and is difficult to determine since many women with such anomalies are not diagnosed, especially if they are asymptomatic or non pregnant. If an additional rudimentary horn exists, a fibrous or fibromuscular band usually connects both horns of the ducts 
but in $80-90 \%$ of cases there is no communication between them [1]. The endometrial cavity in the horn can be functional or non functional.

If the rudimentary horn has a functional endometrium and there is no communication with the main uterine horn or uterine body, haematometra and spasmodic dysmenorrhoea may result. This may be the only clinical sign detected [2, 3]. Associated endometriosis is frequent reported [4]. Non communicating uterine rudimentary horn is associated with decreased evacuation of menstrual bleeding per vagina accentuating retrograde menstruation into the peritoneal cavity and therefore possibly increasing the risk of pelvic endometriosis. However, in cases of mullerian uterine malformations, existence of pelvic endometriosis can not clearly be associated with increased risk of missed miscarriage.

The incidence of unicornuate uterus with a rudimentary horn is estimated between $1 / 100,000$ to $1 / 140,000$ [1]. Conception occurs either from the main uterine cavity or
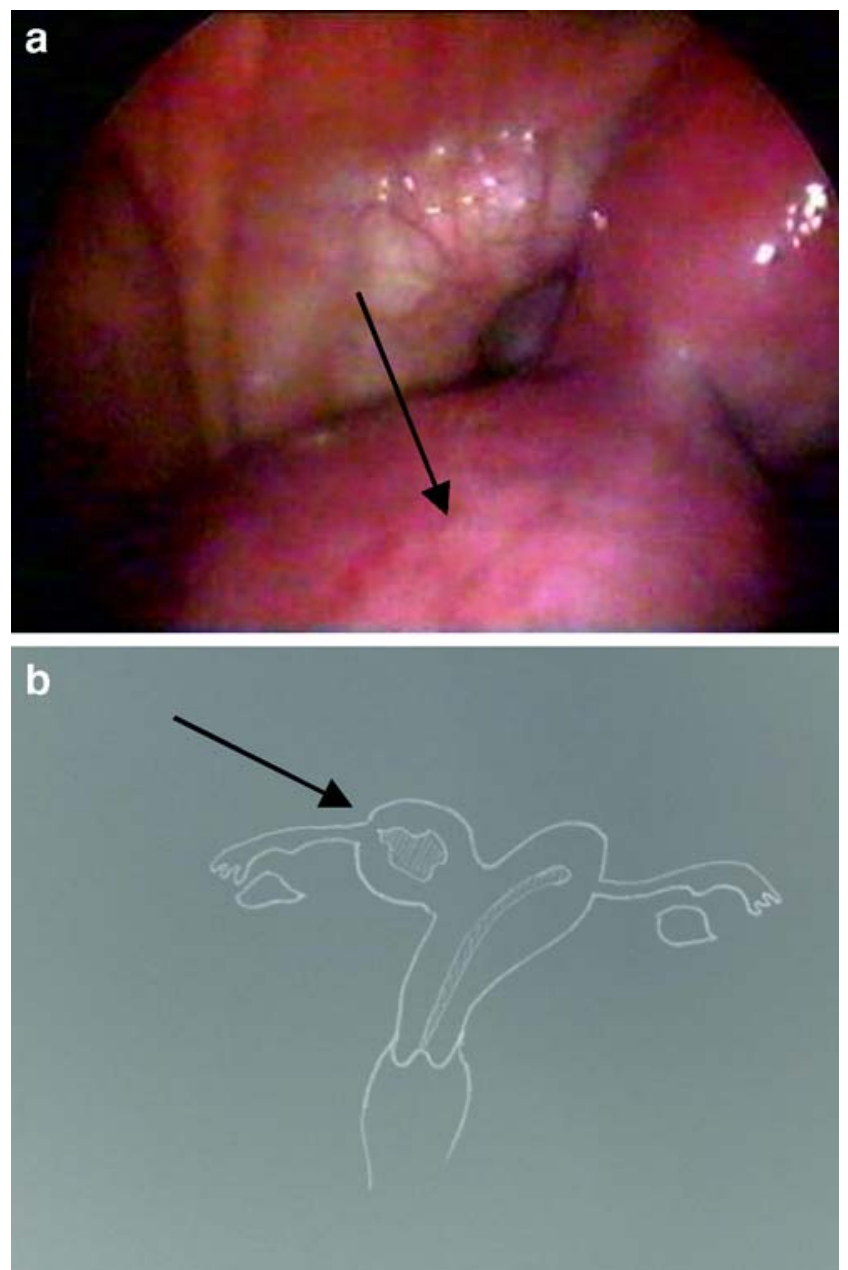

Fig. 1 a Laparoscopic view of the rudimentary horn with pregnancy (arrow). b Schematic representation of the non communicating uterine horn (arrow)

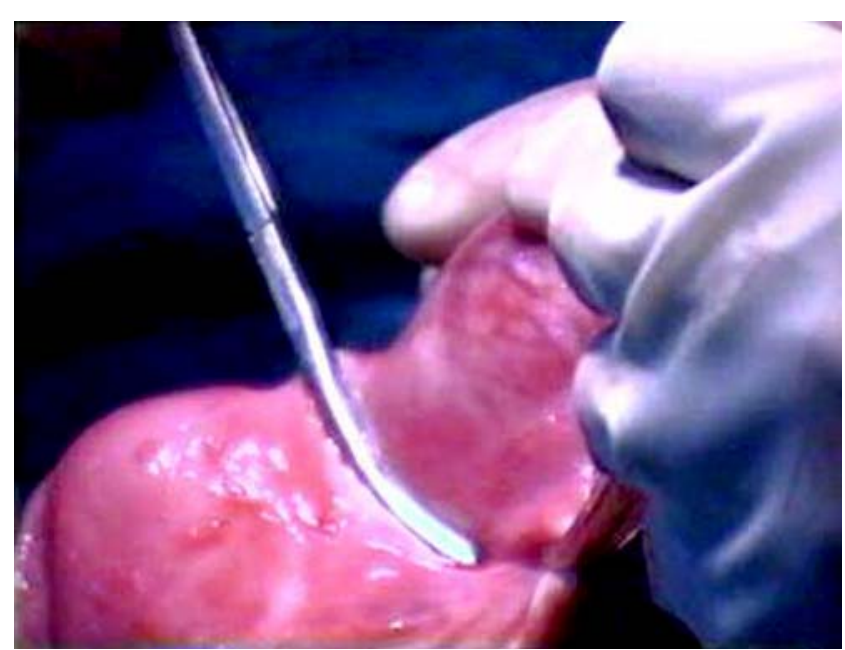

Fig. 2 Excision of the rudimentary horn

from trans-peritoneal migration of the spermatozoa from the controlateral fallopian tube or the fertilised ovum from the ipsi-lateral or controlateral fallopian tube. These pregnancies are characterised by high risk of miscarriage. When the pregnancy exceeds the first trimester there is increased risk of uterine rupture. Over $89 \%$ of such pregnancies end-up experiencing rupture in the 2 nd trimester and only $1 \%$ may succeed with live birth [5]. Uterine rupture in such cases is a serious life threatening situation complicated with maternal haemorrhagic shock [6].

\section{Diagnosis}

Diagnosis of pregnancy in a rudimentary horn can be made by ultrasound scan [7]. Sometimes it is not easy to distinguish between a bicornuate "shape" uterus and an uterus that has a rudimentary horn as in our case. Diagnostic hysteroscopy is one of the best tools for assessing the uterine cavity and needs to be considered in cases of uterine malformations. In addition, hysteroscopy could help the diagnosis of a missed miscarriage in a non communicating horn, confirming the absence of pregnancy in the main uterine cavity. MRI is the most useful complementary investigation in order to distinguish between different uterine structural malformations [7-9]. 3Dultrasound scan can contribute to the diagnosis when available [10]. However, the definitive diagnosis is made by laparoscopy or laparotomy especially in a case of complication with uterine rupture [6].

\section{Management}

In case of a missed miscarriage, a medical approach (mifepristone and misoprostol) has the potential of precipitating uterine rupture in a non communicating horn [11] or 
Fig. 3 Cut section of specimen
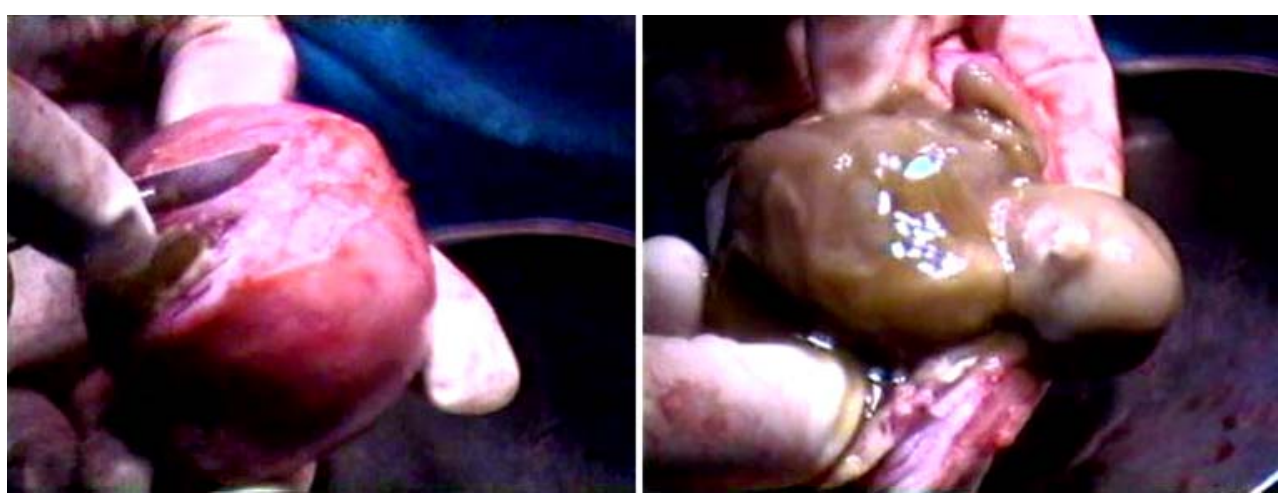

failure and must be avoided if there is suspicion of structural uterine malformation. Use of methotrexate was proposed as an alternative solution in early gestational ( $<7$ weeks) pregnancies [12]. The surgical approach should be organised with the appropriate consent prior to any surgical treatment. Clear explanation and description of the malformation is essential for the patient to understand the theurapeutical approach and risks. Issues such as conservative versus radical treatment, surgical risks and difficulties, and risks of ectopic pregnancy must be discussed prior to any intervention. This is especially relevant in clinical situations where there is no emergency. The surgical approach should be preferable via laparoscopy under experienced hands [2].The laparoscopic approach offers decreased hospital stay and postoperative morbidity [13]. However this approach depends on the availability and experience of the surgeon. Referral to a centre of excellence is advised in asymptomatic patients with delayed miscarriage. Conservative surgical options should be offered especially in nulliparous women. Case reports referred further pregnancies after myotomy and exceresis of the rudimentary horn although prematurity is a significant complication in these pregnancies [14, 15]. The kidneys should be evaluated by ultrasound or intravenous pyelograpfhy because of the high incidence of associated renal abnormalities of about $40 \%$ [16]. The patient needs to be aware of the potential risk of ectopic pregnancy and to be followed as soon as possible in the early assessment unit. If no pregnancy is wanted, contraception advice should be given.

\section{Conclusion}

Delayed miscarriage on congenital uterine malformations in a non communicated rudimentary horn is a rare event and should be managed with caution. Preoperative imaging techniques including ultrasound and MRI are necessary for the assessment of the anatomical malformation. The laparoscopic approach should be considered at first instance.
An effort of conservative treatment and less traumatic surgery should be undertaken in cases of nulliparous or infertile women.

\section{References}

1. Goel P, Aggarwal A, Devi K, Takkar N, Saha PK, Huria A (2005) Unicornuate uterus with non-communicating rudimentary horndifferent clinical presentations. J Obstet Gynecol India 55(2): $155-158$

2. Theodoridis TD, Saravelos H, Chatzigeorgiou KN, Zepiridis L, Grimbizis GF, Vavilis D, Loufopoulos A, Bontis JN (2006) Anatomical variation in the rudimentary horns of a unicornuate uterus: implications for laparoscopic surgery. Reprod Biomed Online 12(1):128-130

3. Von Eye Corleta H, Villodre LC, Reis R, Capp E (2001) Conservative treatment for a non-communicating rudimentary uterine horn. Acta Obstetricia Et Gynecologica Scandinavica 80 (7):668

4. Falcone T, Gidwani G, Paraiso M, Beverly C, Goldberg J (1997) Anatomical variation in the rudimentary horns of a unicornuate uterus: implications for laparoscopic surgery. Hum Reprod 12 (2):263-265

5. O’Leary JL, O’Leary OA (1963) Rudimentary horn pregnancy. Obstet Gynecol 22:371

6. Panayotidis C, Abdel-Fattah M, Leggot M (2004) Rupture of rudimentary uterine horn of a unicornuate uterus at 15 weeks gestation. J Obstet Gynaecol 24(3):323-324

7. Tsafrir A, Rojansky N, Sela HY, Gomori JM, Nadjari M (2005) Rudimentary horn pregnancy: first-trimester prerupture sonographic diagnosis and confirmation by magnetic resonance imaging. J Ultrasound Med 24(2):219-223

8. Pellerito JS, McCarthy SM, Doyle MB et al (1992) Diagnosis of uterine anomalies: relative accuracy of MR imaging, endovaginal sonography and hysterosalpingography. Radiology 183:795

9. Ozeren S, Caliskan E, Corakci A, Ozkan S, Demirci A (2004) Magnetic resonance imaging and angiography for the prerupture diagnosis of rudimentary uterine horn pregnancy. Acta Radiologica 45(8):878-881

10. Salim R, Woelfer B, Backos M, Regan L, Jurkovic D (2003) Reproducibility of three-dimensional ultrasound diagnosis of congenital uterine anomalies. Ultrasound Obstet Gynecol 21 (6):578-582

11. Samuels T-A, Awonuga A (2005) Second-trimester rudimentary uterine horn pregnancy: rupture after labor induction with misoprostol. Obstet Gynecol 106(5 Pt 2):1160-1162 
12. Edelman AB, Jensen JT, Lee DM, Nichols MD (2003) Successful medical abortion of a pregnancy within a noncommunicating rudimentary uterine horn. Am J Obstet Gynecol 189(3):886-887

13. Laufer MR (1997) Laparoscopic resection of obstructed hemiuteri in a series of adolescents. J Pediatr Adolesc Gynecol $10: 163$
14. Heinonen PK (1997) Unicornuate uterus and rudimentary horn. Fertil Steril 68(2):224-230

15. Akar ME, Bayar D, Yildiz S, Ozel M, Yilmaz Z (2005) Reproductive outcome of women with unicornuate uterus. Aust N Z J Obstet Gynaecol 45(2):148-150

16. Fedele L, Bianchi S, Agnoli B et al (1996) Urinary tract anomalies associated with unicornuate uterus. J Urol 155:847 